\title{
Neonatal and infantile appendicitis still confuses minds: report of two cases
}

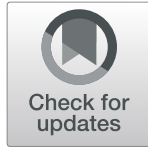

Mustafa Okumuş ${ }^{1,2^{*}}$ id and Adil Umut Zübarioğlu²

\begin{abstract}
Background: Acute appendicitis is extremely rare in the neonatal and infantile periods. The number of cases published in the last century is just over 100. Mortality and morbidity are still high due to diagnostic problems because there are no specific clinical features and reliable investigation for the diagnosis. Herein, we present two patients to remind physicians that the diagnosis of neonatal and infantile appendicitis should always be kept in mind.

Case presentations: A 30 3/7-week-old 740-g newborn girl was delivered by cesarean section because of preeclampsia. The newborn was followed in the neonatal intensive care unit and fed with an orogastric catheter. An abdominal distention developed on the 18th day of her life. While following up with a preliminary diagnosis of necrotizing enterocolitis, she was operated on the 4th day due to abdominal free air seen on X-ray. A perforated appendicitis was detected in the abdominal exploration and formal appendectomy was performed. Histology demonstrated marked transmural inflammation and necrosis at the perforated site and there was no evidence of Hirchsprung's disease. The patient was started on breast milk on the third postoperative day and discharged home on day 98.

A 3.5-month-old boy was admitted to our clinic because of abdominal distention, discomfort, and constipation which had been ongoing for 4 days. He was followed up as an outpatient basis for 4 days in another center with the diagnosis of infantile colic. An increase in echogenicity due to intense inflammation was observed in mesenteric plans using USG in the right lower quadrant of the abdomen. Following preoperative preparations, the patient underwent abdominal exploration and appendectomy. He had an uneventful recovery and pathologic examination demonstrated a necrotizing appendicitis with perforation. He was discharged on the fourth postoperative day without any problems.

Conclusion: It is a fact that acute appendicitis in neonates and infants may not be diagnosed easily and quickly as in older children because there are no specific clinical features and reliable investigation for the diagnosis. Delay in diagnosis and treatment often results in appendicular perforation and peritonitis. The main safeguard against mortality and morbidity remains a high index of suspicion.
\end{abstract}

Keywords: Acute appendicitis, Newborn, Infant, Peritonitis, Appendicular perforation, Case report

\footnotetext{
* Correspondence: drmustafaokumus@gmail.com

'Department of Pediatric Surgery, Faculty of Medicine, Gaziosmanpaşa

Hospital, Yeni Yüzyıl University, Gaziosmanpaşa, Istanbul, Turkey

2Department of Pediatrics, Division of Neonatology, Faculty of Medicine,

Gaziosmanpaşa Hospital, Yeni Yüzyıl University, Gaziosmanpaşa, Istanbul,

Turkey
}

(c) The Author(s). 2020 Open Access This article is licensed under a Creative Commons Attribution 4.0 International License, which permits use, sharing, adaptation, distribution and reproduction in any medium or format, as long as you give appropriate credit to the original author(s) and the source, provide a link to the Creative Commons licence, and indicate if changes were made. The images or other third party material in this article are included in the article's Creative Commons licence, unless indicated otherwise in a credit line to the material. If material is not included in the article's Creative Commons licence and your intended use is not permitted by statutory regulation or exceeds the permitted use, you will need to obtain permission directly from the copyright holder. To view a copy of this licence, visit http://creativecommons.org/licenses/by/4.0/. 


\section{Background}

Acute appendicitis, a disease of any age, is extremely rare in the neonatal and infantile periods [1]. It is referred to by case presentations rather than large case series in the literature. The number of cases published in the last century is just over 100 [2]. Mortality and morbidity are still high due to the diagnostic problems most of the time. Even though mortality tends to decrease over time, it is still around $28 \%[2,3]$. On the other hand, the diagnostic difficulties continue unchanged. Herein, we presented two patients to remind that the diagnosis of neonatal and infantile appendicitis should always be kept in mind.

\section{Case presentation 1}

A 30 3/7-week-old 740-g newborn girl was delivered by cesarean section because of preeclampsia. The newborn was followed in the neonatal intensive care unit and fed with an orogastric catheter. Due to the respiratory distress that started on day 18 of life, supplementary oxygen treatment was started. The abdomen was normal with palpation. C-reactive protein (CRP) was $9.7 \mathrm{mg} / \mathrm{L}$ and the white blood cell count (WBC) was normal. On day 19, abdominal distension developed and orogastric feeding was stopped. Dilated intestinal loops were revealed in abdominal X-ray. The WBC count was normal and CRP was $90.2 \mathrm{mg} / \mathrm{L}$. On day 20, abdominal X-ray was the same but the patient had bloody stool. There was no evidence of pneumatosis intestinalis. The patient had anemia and thrombocytopenia in addition to high CRP $(292 \mathrm{mg} / \mathrm{L})$. Twenty milliliters of erythrocyte suspension was given. Gastric decompression continued with a reasonable volume. Antibiotic treatment was changed to broad-spectrum antibiotics and pentoxifylline was added to the treatment with a preliminary diagnosis of necrotizing enterocolitis (NEC). On day 21, CRP began to decrease $(117 \mathrm{mg} / \mathrm{L})$ but the abdominal distention remained unchanged. No significant features were

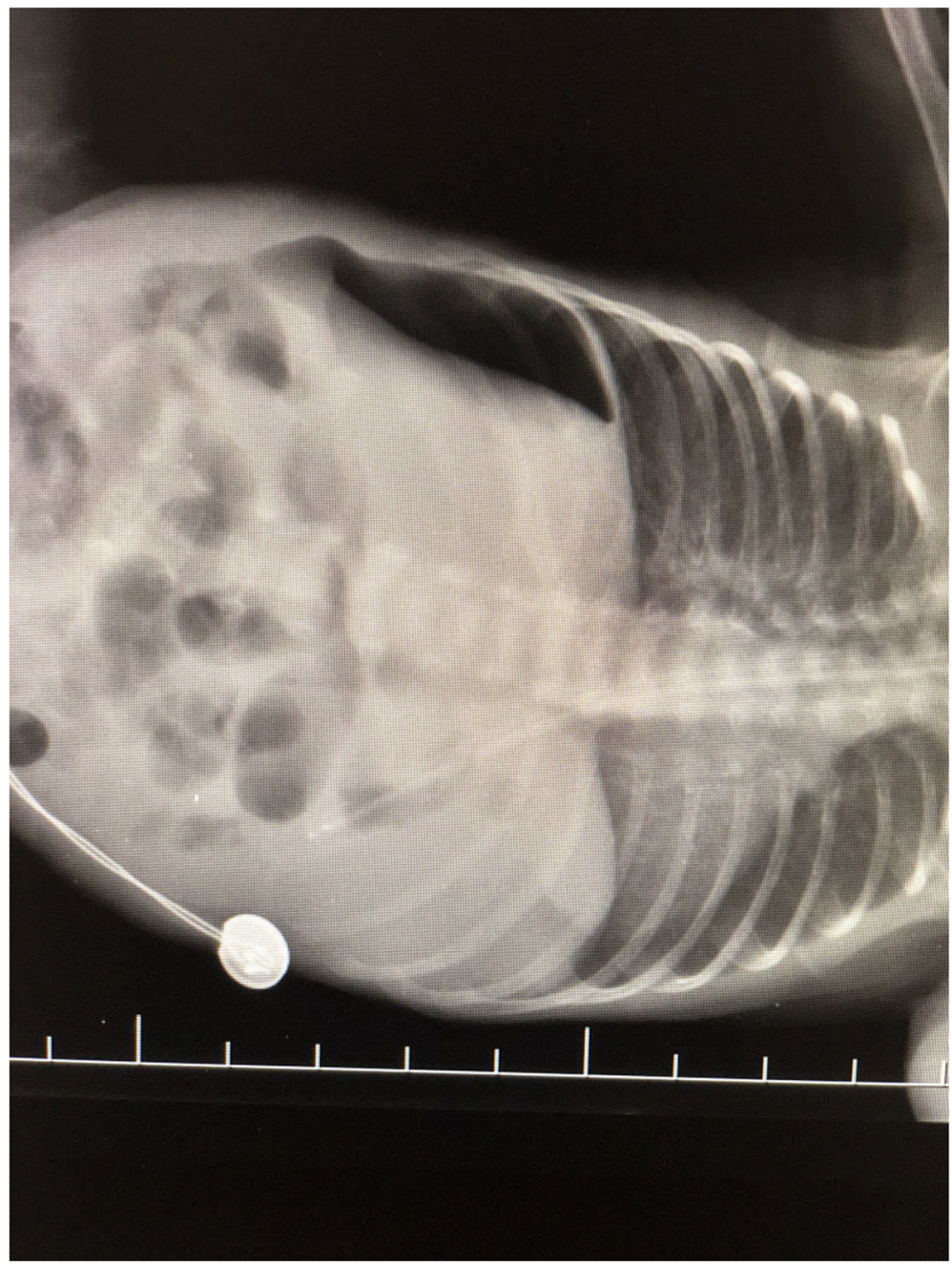

Fig. 1 Intraperitoneal free air indicating perforation 
detected on abdominal X-ray except dilated intestinal loops. On day 22, CRP was the same but the patient had fever. Tenderness was detected with an abdominal examination. Abdominal X-ray revealed free peritoneal air (Fig. 1). Fifteen milliliters of erythrocyte suspension was given and the patient was prepared for surgery. The patient weighed $1040 \mathrm{~g}$ when taken to the operating room. The patient's bowel appeared viable with no evidence of necrotizing enterocolitis. There was exudate in the right lower quadrant. The appendix looked inflamed and perforated proximally (Fig. 2). An appendectomy was performed. Postoperative recovery was smooth and uneventful. Histology demonstrated marked transmural inflammation and necrosis at the perforated site and there was no evidence of Hirchsprung's disease (HD). The patient was started on breast milk on the third postoperative day and discharged home on day 98 . The girl now aged 1 year and doing well.

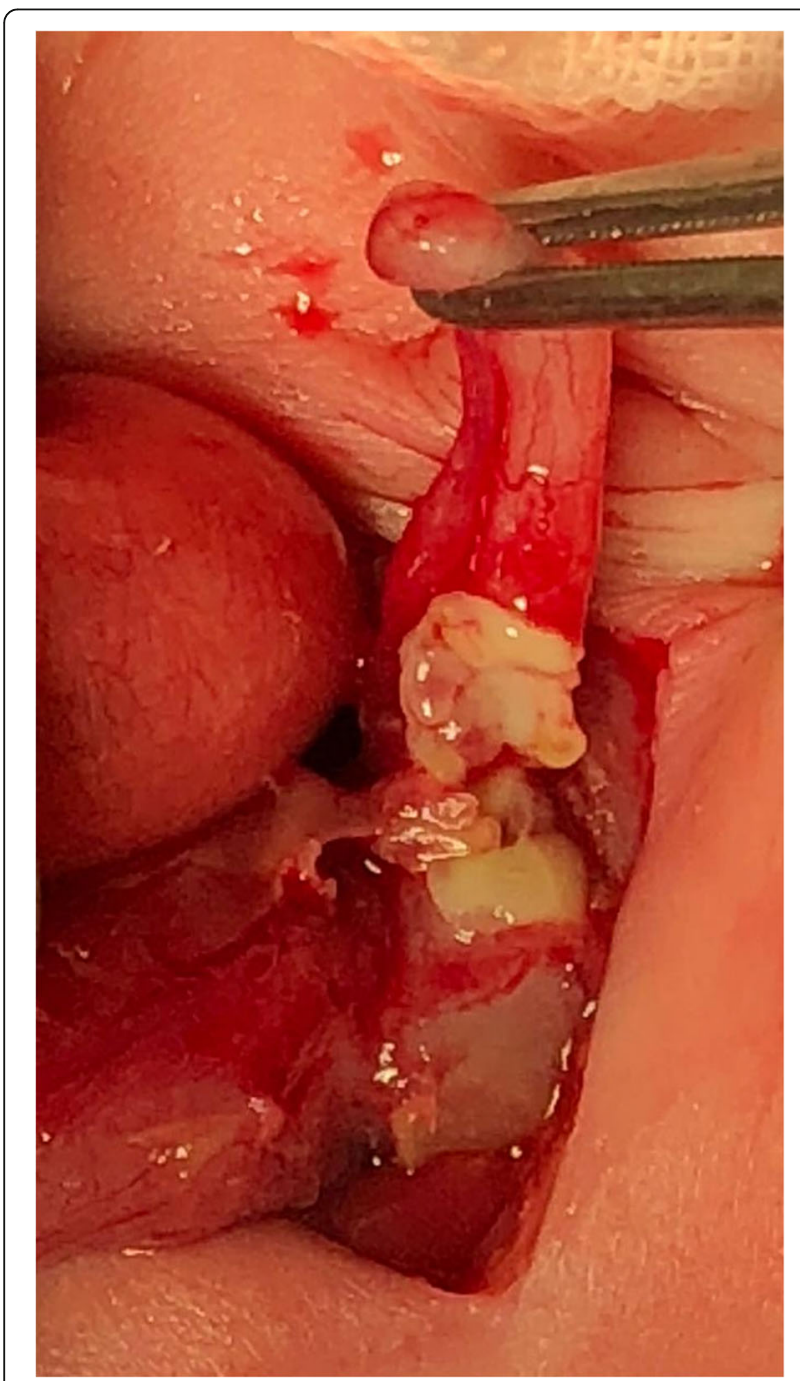

Fig. 2 Appendicular perforation

\section{Case presentation 2}

A 3.5-month-old boy was admitted to our clinic because of abdominal distention, discomfort, and constipation, which had been ongoing for 4 days. On the first day, he was diagnosed as having infantile colic and was sent home. On the second day, he was admitted to the hospital again because of anorexia. No problem was detected in the examination and the patient was sent home again. On the third day, vomiting was added to the symptoms. The patient was admitted to another clinic. No pathology was detected with ultrasonography (USG) but abdominal X-ray revealed dilated intestinal loops (Fig. 3). WBC count was found normal $\left(7.7 \times 10^{9} / \mathrm{L}\right)$ and CRP was found high $(134 \mathrm{mg} / \mathrm{L})$ in laboratory investigations. Conservative follow-up in hospital was recommended but the patient's parents did not accept hospitalization. On the fourth day, the patient was admitted to our clinic due to continued symptoms. On examination, abdominal distension and tenderness were detected in the right lower quadrant. The WBC count was normal and CRP was $177 \mathrm{mg} / \mathrm{L}$. An increase in echogenicity due to intense inflammation was observed in mesenteric plans using USG in the right lower quadrant of the abdomen. In addition, an uncompressed bowel loop was detected in the right lower quadrant, which could be compatible with the appendix. Following preoperative preparations, the patient underwent abdominal exploration and appendectomy. During the operation, ileal loops were collected around the cecum and widespread inflammation was observed in that area. When the ileal loops were removed, it was seen that the appendix was inflamed and perforated. He had an uneventful recovery and pathologic examination demonstrated a necrotizing appendicitis with perforation. $\mathrm{He}$ was discharged on the fourth postoperative day without any problems.

\section{Discussion}

Although acute appendicitis is the most common cause of acute abdomen in childhood, it is very rare in the neonatal period with a reported incidence of $0.04 \%$ [2, 4, $5]$. This rare occurrence was classically explained by some factors such as funnel-shaped appendix, a diet of soft foods, recumbent posture, and infrequent infections $[2,4]$. However, the problem is that many neonatal appendicitis (NA) cases are still diagnosed late or undiagnosed. The question is an issue to be considered; is it really rare or can we not diagnose it because we continue to consider NEC as the first diagnosis in newborns with abdominal distension and vomiting, whether term or preterm? On the other hand, infantile colic becomes prominent as a diagnosis in infants. Some patients with NA die because of misdiagnosis before undergoing a surgical exploration. 


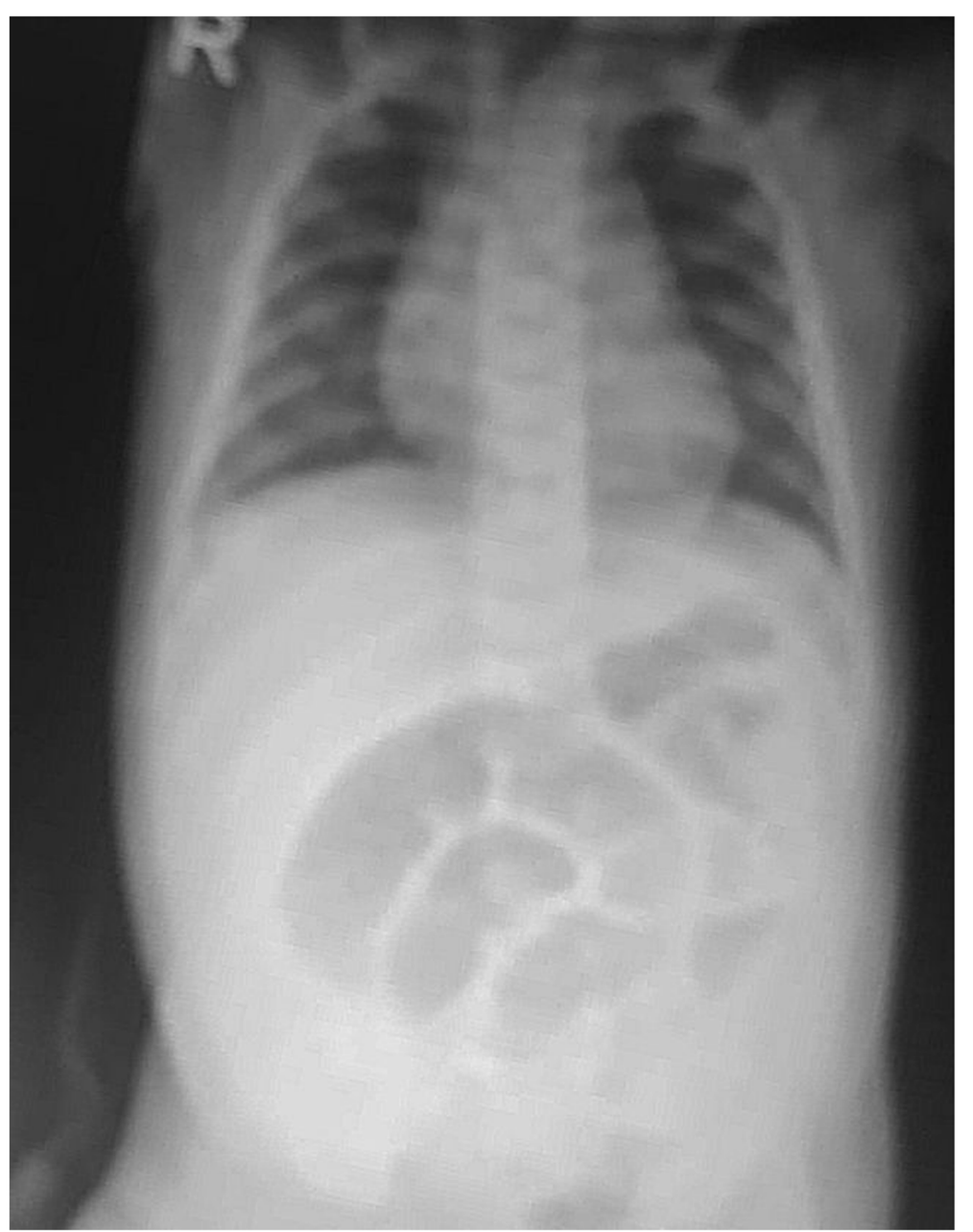

Fig. 3 Dilated bowel loops indicating that there may be a problem in the abdomen

Karaman et al. reported that neonatal appendicitis was found intra abdominally in three-quarters of patients and in an inguinal hernia sac in one-quarter of patients, and occurred in males approximately $75 \%$ of the time [2]. These results came from scanning nearly 100 years of literature. However, when the last 30 years of cases are evaluated, it could be said that the female/male ratio is closer to each other. This result has been supported by both Raveenthiran and Huang et al. in recent years $[1,5]$. At the same time, Huang et al. showed that there was no significant change in the rate of Amyand's hernia in a series of 31 cases they recently published [5]. We cannot comment on this issue with two cases, but at least we can contribute to this result.

There are three important etiologic causes that are discussed classically. First, it is considered to be an isolated form of NEC because it is more common in preterms [6-8]. However, we know from recent publications that neonatal appendicitis is more common in term babies than in preterms and the appearance of the intestines during surgery is generally normal $[1,5]$. Second, hypoxic conditions, such as perinatal asphyxia, congenital heart disease, ECMO, or other low flow states, are said to be important in the etiology [4]. It could be thought that the first and second reason are related to each other because we know that these situations are also risk factors for NEC. Although they are different diseases, they are somehow related to each other and deserve further investigations [9]. Thirdly, some authors think that cecal distention with increased pressure caused by some diseases is important in the etiology $[2,4,6,10]$. Although $\mathrm{HD}$ and meconium ileus (MI) are the first to suspect, we see that the coexistence of these diseases with neonatal appendicitis is very rare when the reported cases of NA are evaluated $[1,5]$. The pathology results of our patient were also not compatible with HD.

Abdominal distention, vomiting, feed refusal, and fever are the most common symptoms of appendicitis, but we encounter these very often in newborns and they are not specific to any disease $[3,5]$. WBC count is generally 
normal. The increase in CRP values can be considered to be important because it gradually increases in most cases, as in our patients. Many authors suggest the use of USG as an initial imaging modality [3], but it often does not detect significant pathology in NA. Therefore, the diagnosis of NA is delayed most of time. Although computed tomography $(\mathrm{CT})$ can also be a very useful diagnostic tool, it is less frequently used initially because of the exposure to radiation [3]. We mostly prefer exploration instead of CT in the late period. On the other hand, plain radiography does not help diagnose appendicitis, but at least shows complications such as perforations [5]. In most cases, free air in the peritoneum is the most important finding providing for early exploration such as in our first patient.

The consequence of delay in diagnosis is inevitably high mortality and morbidity. Mortality was $70 \%$ in the beginning of the 20th century, and decreased to $25-28 \%$ in the early 2000s [2]. Mortality in the newly published 31-case series of Huang et al. was 0\% [5]. Considering the new case reports and the two patients we reported, we think that mortality is much lower today [2, 4-10]. However, we cannot explain this decline in mortality by early diagnosis because preoperative diagnosis of acute appendicitis is very low and perforation rates are still high. The decrease in mortality and morbidity can only be explained by the improvements in intensive care.

\section{Conclusions}

It is a fact that acute appendicitis in newborns and infants is not diagnosed easily and quickly as in older children because there are no specific clinical features and reliable investigation for the diagnosis. Delay in diagnosis and treatment often results in appendicular perforation and peritonitis. The main safeguard against mortality and morbidity remains a high index of suspicion.

\section{Abbreviations \\ CRP: C-reactive protein; WBC: White blood cell count; NEC: Necrotizing enterocolitis; HD: Hirschsprung's disease; USG: Ultrasonography; NA: Neonatal appendicitis; ECMO: Extracorporeal membrane oxygenation; MI: Meconium ileus; CT: Computed tomography}

\section{Authors' contributions}

$\mathrm{MO}$ conceived the study and participated in its design; $\mathrm{MO}$ and AUZ participated in data acquisition; $\mathrm{MO}$ and $\mathrm{AUZ}$ participated in the analyses and interpretation of data; $\mathrm{MO}$ drafted the manuscript; $\mathrm{MO}$ and $\mathrm{AUZ}$ performed critical revision. All authors read and approved the final manuscript.

\section{Funding}

None

Availability of data and materials

Data available upon request.

\section{Ethics approval and consent to participate}

Since the patients concerned are newborns, a written consent was taken from parents before operation in all cases. All procedures performed in studies involving human participants were conducted in accordance with the ethical standards of the institutional and/or national research committee and with the 1964 Helsinki Declaration and its later amendments or comparable ethical standards.

\section{Consent for publication}

Patient identity did not appear in any part of the manuscript; therefore, consent for publication was not required.

\section{Competing interests}

The authors declare that they have no competing interest.

Received: 7 May 2020 Accepted: 26 June 2020

Published online: 20 August 2020

References

1. Raveenthiran V. Neonatal appendicitis (part 1): a review of 52 cases with abdominal manifestation. J Neonatal Surg. 2015;4(1):4.

2. Karaman A, Çavuşoğlu YH, Karaman I, Çakmak Ö. Seven cases of neonatal appendicitis with a review of the English language literature of the last century. Pediatr Surg Int. 2003;19(11):707-9.

3. Schwartz KL, Gilad E, Sigalet D, Yu W, Wong AL. Neonatal acute appendicitis: a proposed algorithm for timely diagnosis. J Pediatr Surg. 2011:46(11):2060-4.

4. Jancelewicz T, Kim G, Miniati D. Neonatal appendicitis: a new look at an old zebra. J Pediatr Surg. 2008;43(10):e1-5.

5. Huang X, Huang X, Mbugi J, Wei L, Ziyu H, Ya H, et al. An experience with 31 cases of neonatal appendicitis: a retrospective study. J Neonatal Surg. 2019;8(3):21

6. Mammou S, Ayadi I, Hamida EB, Marrakchi Z. Acute neonatal appendicitis in a preterm. Afr J Paediatr Surg. 2015;12(4):294-5.

7. Bose $\mathrm{S}$, Wakeman D. Perforated appendicitis in a preterm neonate: a case report with a literature review Case Studies in Surgery 2017;3(4): 6-10.

8. Naito T, Teramen H, Hayashi H, Takegawa M, Sakamoto H, Shimada T, et al. Colon stenosis due to acute neonatal appendicitis in a preterm baby: a case report. BMC Pediatr. 2019;19:492.

9. Haider F, Ayoub B, Al Kooheji M, Al Juffairi M, Al Shaikh S. Perforated acute appendicitis with no peritonitis in a preterm baby: a case report. J Med Case Rep. 2017:11:125

10. El-Gohary ME. Al juburi S, neonatal appendicitis with perforation: a case report. J Ped Surg Case Reports. 2014;2:353-4.

\section{Publisher's Note}

Springer Nature remains neutral with regard to jurisdictional claims in published maps and institutional affiliations.

\section{Submit your manuscript to a SpringerOpen ${ }^{\circ}$ journal and benefit from:}

- Convenient online submission

- Rigorous peer review

- Open access: articles freely available online

High visibility within the field

- Retaining the copyright to your article

Submit your next manuscript at $>$ springeropen.com 